\title{
Bromine and Chlorine Determination in Cigarette Tobacco using Microwave-Induced Combustion and Inductively Coupled Plasma Optical Emission Spectrometry
}

\author{
Aline L. H. Müller, ${ }^{a, b}$ Cezar A. Bizzi, ${ }^{a, b}$ Juliana S. F. Pereira, ${ }^{a, b}$ Marcia F. Mesko, ${ }^{c}$ \\ Diogo P. Moraes, ${ }^{d, b}$ Erico M. M. Flores ${ }^{a, b}$ and Edson I. Muller ${ }^{*, a, b}$ \\ ${ }^{a}$ Departamento de Química, Universidade Federal de Santa Maria, 97105-900 Santa Maria-RS, Brazil \\ ${ }^{b}$ Instituto Nacional de Ciência e Tecnologia de Bioanalítica, Campinas-SP, Brazil \\ 'Instituto de Química e Geociências, Universidade Federal de Pelotas, 96010-610 Pelotas-RS, Brazil \\ ${ }^{d}$ Instituto de Química, Universidade Federal do Rio Grande do Sul, 91501-970 Porto Alegre-RS, Brazil
}

\begin{abstract}
A combustão iniciada com micro-ondas (MIC) foi aplicada para decomposição de amostras de tabaco de cigarro e subsequente determinação de bromo e cloro por espectrometria de emissão óptica com plasma indutivamente acoplado (ICP OES). Massas de amostra de até $500 \mathrm{mg}$ foram decompostas em frascos fechados e pressurizados com 20 bar de oxigênio. A combustão foi completada em menos de $30 \mathrm{~s}$ e os analitos foram absorvidos em solução diluída de $\left(\mathrm{NH}_{4}\right)_{2} \mathrm{CO}_{3}$. A exatidão foi avaliada usando materiais de referência certificados e mediante a determinação utilizando ICP-MS. A concordância foi melhor do que $98 \%$ usando $50 \mathrm{mmol} \mathrm{L}^{-1}$ de $\left(\mathrm{NH}_{4}\right)_{2} \mathrm{CO}_{3}$ como solução absorvedora e 5 min de refluxo. A temperatura durante a combustão foi superior a $1400{ }^{\circ} \mathrm{C}$ e o conteúdo de carbono residual nos digeridos após MIC foi menor que $1 \%$. Até oito amostras podem ser decompostas simultaneamente. Limites de quantificação utilizando MIC e determinação por ICP OES foram de 12 e $6 \mu \mathrm{g} \mathrm{g}^{-1}$ para $\mathrm{Br}$ e $\mathrm{Cl}$, respectivamente.
\end{abstract}

The microwave-induced combustion (MIC) was applied for cigarette tobacco samples digestion and further determination of bromine and chlorine by inductively coupled plasma optical emission spectrometry (ICP OES). Samples masses up to $500 \mathrm{mg}$ were combusted in closed vessels using 20 bar of oxygen. Combustion was complete in less than $30 \mathrm{~s}$ and analytes were absorbed in diluted $\left(\mathrm{NH}_{4}\right)_{2} \mathrm{CO}_{3}$ solution. Accuracy was evaluated using certified reference materials with similar matrix composition and comparison with results obtained using ICP-MS. The agreement was better than $98 \%$ using $50 \mathrm{mmol} \mathrm{L}^{-1}\left(\mathrm{NH}_{4}\right)_{2} \mathrm{CO}_{3}$ as absorbing solution and $5 \mathrm{~min}$ of reflux. Temperature during combustion was higher than $1400^{\circ} \mathrm{C}$ and the residual carbon content in digest obtained after MIC was lower than $1 \%$. Up to eight samples could be processed simultaneously and a single absorbing solution was suitable for both $\mathrm{Br}$ and $\mathrm{Cl}$. Limit of quantification by MIC and further ICP OES determination was 12 and $6 \mu \mathrm{g} \mathrm{g}^{-1}$ for $\mathrm{Br}$ and $\mathrm{Cl}$, respectively.

Keywords: microwave-induced combustion, cigarette, bromine, chlorine, ICP OES

\section{Introduction}

Tobacco leaves may be used in different forms such as smoking, chewing or sniffing. All of these forms result in a number of negative side effects on human health that are well-documented. ${ }^{1}$ Chlorine and bromine are essential for growth of the plants and minor constituents of tobacco. The content of bromine and chlorine in tobacco could vary depending on tobacco type, soil and climatic

*e-mail: edson_muller@yahoo.com.br conditions. Typical concentration ranges for $\mathrm{Br}$ and $\mathrm{Cl}$ reported in tobacco are 100 to 200 and 700 to $30000 \mathrm{\mu g} \mathrm{g}^{-1}$, respectively. Over $85 \%$ of the all halogenated compounds found in tobacco and smoke are either halogenated agrochemicals, impurities found in the agrochemicals, or decomposition products from the agrochemicals. Up to $2.4 \%$ of the bromine and chlorine can be transferred to smoke. There are 242 identified halogenated compounds in tobacco and/or tobacco smoke and chlorine and bromine are present in 192 and 12 different compounds, respectively. ${ }^{2}$ 
Several analytical methods have been used for $\mathrm{Br}$ and $\mathrm{Cl}$ determination in biological samples, such as neutron activation analysis, ${ }^{3,4}$ total reflection X-ray fluorescence, $, 5,6$ inductively coupled plasma optical emission spectrometry $(\mathrm{ICP} \mathrm{OES})^{7}$ and inductively coupled plasma mass spectrometry (ICP-MS) ${ }^{8-10}$ Instrumental neutron activation analysis (INAA) is a sensitive method for the determination of metals and non metals and has been accepted worldwide for tobacco analysis because it is easy to handle solid samples and produces little gas during irradiation. However, neutron activation requires a neutron flux source that limits its applicability for most of laboratories. ${ }^{11}$

Total reflection X-ray fluorescence has been used to the determination of halogens in tobacco. However, this technique is prone to interferences related to matrix composition that can affect the accuracy. ${ }^{12}$ Inductively coupled plasma optical emission spectrometry and inductively coupled plasma mass spectrometry allow the determination of halogen providing suitable sensitivity and selectivity even at trace and ultra trace concentrations. In this sense, a complete digestion or extraction step is required before the determination. In general, extraction procedures with water have been used for halogens release from the matrix (especially for $\mathrm{Cl}$ ) and further determination by potentiometric titration using silver nitrate solution. However, sometimes a complete extraction of halogens cannot be achieved and the titrimetric procedure with silver nitrate does not allow distinguishing for chlorine and bromine. ${ }^{13-15}$

The sample preparation step for tobacco digestion presents specific difficulties. Usually, tobacco digestion requires the use of mineral oxidizing acids (e.g. concentrated nitric acid) in order to obtain a more effective digestion. ${ }^{16}$ This procedure can result in analyte losses due to volatility of chlorine and bromine generally as $\mathrm{HX}(\mathrm{X}=\mathrm{Cl}$ and $\mathrm{Br})$ even using closed vessels. ${ }^{17-19} \mathrm{In}$ addition, the presence of high acid concentration in digests cannot be supported by some analytical techniques, such as ICP OES ${ }^{20}$ and ICP-MS. ${ }^{21}$ On the other hand, combustion procedures are particularly suitable to decompose organic materials with high carbon content because of the high temperature achieved. ${ }^{22}$ In this case, diluted alkaline solutions can be used avoiding the normal requirement of concentrated reagents.

In recent years an important improvement in combustion methods was the development of microwave-induced combustion (MIC) system. This system combines some advantages of classical combustion procedures with those presented by conventional closed systems heated by microwave radiation..$^{23}$ This procedure is performed in the same system conventionally used for microwaveassisted wet digestion and the only instrumental change is a small quartz sample holder which is placed inside the quartz vessel. A reflux step can be applied after combustion, assuring an effective washing of vessel walls and holder surface, which is a great advantage over the classic combustion systems, where the cleaning step of the vessel must be performed manually. This method has been successfully applied for digestion of biological samples, ${ }^{24,25}$ elastomers, ${ }^{26}$ coal $^{27}$ and crude oil products ${ }^{28-33}$ for subsequent metal and halogens determinations.

In this work different cigarette tobacco samples were digested by $\mathrm{MIC}$ and further $\mathrm{Br}$ and $\mathrm{Cl}$ determination was performed by ICP OES. Determination of $\mathrm{Br}$ and $\mathrm{Cl}$ in MIC digests was also carried out using ICP MS. Sample mass, type and concentration of absorption solution were investigated and the efficiency of decomposition procedure was checked by the residual carbon content determination in digests. The residual carbon content was also determined using ICP OES by monitoring the carbon emission line at $193.091 \mathrm{~nm} .{ }^{34}$ The accuracy was evaluated using certified reference materials (CRM) with similar matrix composition. Recovery tests were also performed for both analytes. For comparison of results the determination of $\mathrm{Br}$ and $\mathrm{Cl}$ was also carried out using ICP-MS.

\section{Experimental}

\section{Samples and reagents}

Eight different cigarette samples from two different manufacturers were purchased in a local store. Firstly, cigarette filters and paper were removed and tobacco was ground in a cryogenic mill (Spex Certiprep, model 6750 Freezer Mill, Metuchen, NJ, EUA). Samples were frozen in liquid argon during $2 \mathrm{~min}$ and further ground during $2 \mathrm{~min}$. The following certified reference materials (CRMs) were used for accuracy evaluation: Virginia tobacco leaves and Oriental tobacco leaves (CTA-VTL-2 and CTA-OTL-1, respectively, Polish certified reference material, Institute of Nuclear Chemistry and Technology, Poland), peach leaves (NIST 1547, National Institute of Standards \& Technology, USA) and aquatic plant (BCR 60, Community Bureau of Reference, Brussels). All samples and CRMs were pressed as pellets (diameter of $13 \mathrm{~mm}$ ) using a hydraulic press set at 3 ton by $1 \mathrm{~min}$ (Specac, Orpington, UK). A sample with lower $\mathrm{Br}$ and $\mathrm{Cl}$ content (sample $\mathrm{G}$ ) was used for spike studies and for optimization of the absorbing solution.

Water was firstly distilled and subsequently deionized $(18.2 \mathrm{M} \Omega \mathrm{cm})$ and analytical-grade reagents (Merck, Darmstadt, Germany) were used throughout. For the determination by ICP OES and ICP-MS standard solutions were prepared in an appropriated concentration of $\left(\mathrm{NH}_{4}\right)_{2} \mathrm{CO}_{3}$ solution. Ammonium nitrate solution $\left(6 \mathrm{~mol} \mathrm{~L}^{-1}\right)$ 
was used as an ignition aid. A small disc of filter paper (15 $\mathrm{mm}$ in diameter, $12 \mathrm{mg}$ ) with low ash content (Black Ribbon Ashless, Schleicher \& Schuell GmbH, Dassel, Germany) was used as aid for the combustion process. The filter paper was previously cleaned with absolute ethanol for $20 \mathrm{~min}$ in an ultrasonic bath and rinsed with water and dried in an oven for $2 \mathrm{~h}$ at $60{ }^{\circ} \mathrm{C}$ before use.

Water and diluted ammonium carbonate solutions were used as absorbing solutions for $\mathrm{Br}$ and $\mathrm{Cl}$ in $\mathrm{MIC}$ procedure. Ammonium carbonate was dissolved in water with final concentration ranging from 5 to $100 \mathrm{mmol} \mathrm{L}^{-1}$. Glass or quartz materials were soaked in $1.4 \mathrm{~mol} \mathrm{~L}^{-1} \mathrm{HNO}_{3}$ for $24 \mathrm{~h}$ and thoroughly washed with water before use.

\section{Instrumentation}

A Multiwave 3000 microwave sample preparation system (Anton Paar GmbH, Graz, Austria) equipped with high-pressure quartz vessels (internal volume of $80 \mathrm{~mL}$, maximum temperature and pressure of $280^{\circ} \mathrm{C}$ and 80 bar, respectively) was used in this study for proposed combustion procedure. The software version was v1.27-Synt and the microwave system was previously modified to run with a maximum pressure rate of $3 \mathrm{bar} \mathrm{s}^{-1}$ (and not $0.8 \mathrm{bar} \mathrm{s}^{-1}$ as in the original software). This change was necessary to prevent eventual interruption of the microwave irradiation before all the samples start the combustion. Pressure was monitored in each vessel for all the runs. A specially designed quartz device was used as sample holders for the MIC procedure. This device was developed in order to facilitate the oxygen diffusion by the pressed sample and to reduce the cool surfaces that might cause carbon deposits in the quartz surface. ${ }^{35}$

An inductively coupled plasma optical spectrometer model Spectro Ciros CCD simultaneous spectrometer with axial view configuration (Spectro Analytical Instruments,
Kleve, Germany) was used for $\mathrm{Br}, \mathrm{Cl}$ and residual carbon determination. A crossflow nebulizer coupled to a Scott double pass type nebulization chamber was used throughout. Plasma operating conditions used in this work were a radio-frequency power generator of $1700 \mathrm{~W}$, and argon flow rates of plasma, auxiliary and nebulizer were 14.0, 1.00 and 1.00 $\mathrm{L} \mathrm{min}^{-1}$, respectively. The selected wavelengths used for $\mathrm{Br}, \mathrm{Cl}$ and $\mathrm{C}$ determinations were 154.065, 134.724 and $193.091 \mathrm{~nm}$, respectively. Argon of $99.996 \%$ purity (WhiteMartins, Praxair, São Paulo, Brazil) was used for plasma generation, nebulization and as auxiliary gas for the halogen determination (Table 1).

Halogen determinations by ICP OES were compared using an inductively coupled plasma mass spectrometer (PerkinElmer-SCIEX, Model Elan DRC II, Thornhill, Canada) equipped with a concentric nebulizer (Meinhard Associates, Golden, CA, USA), a baffled cyclonic spray chamber (Glass Expansion, Inc., West Melbourne, Australia) and a quartz torch with a quartz injector tube ( $2 \mathrm{~mm}$ i.d.) was used for the determination of $\mathrm{Br}$ and $\mathrm{Cl}$ after MIC. Instrumental performance optimization, including nebulizer gas flow rate, RF power and ion lens voltage, was performed and operational conditions are described in Table 1. Chlorine determination by ICP-MS was performed with DRC using ammonia (purity higher than $99.999 \%$ ) as reaction gas. The DRC parameters were adjusted in order to minimize the interferences on ${ }^{35} \mathrm{Cl}^{+}$isotope according to previous work. ${ }^{36}$

The temperature during cigarette tobacco samples combustion was determined using an optical pyrometer (Ultimax Infrared Thermometer, Ircon, Niles, IL, USA) equipped with a close-up VX-CL1 lens.

\section{Proposed microwave-induced combustion procedure}

The operation conditions for the proposed MIC procedure were evaluated using cigarette tobacco pellets

Table 1. Operational conditions of halogens determination by ICP OES and ICP-MS

\begin{tabular}{|c|c|c|}
\hline Parameter & ICP OES & ICP-MS \\
\hline RF power / W & 1700 & 1400 \\
\hline Plasma gas flow rate / $\left(\mathrm{L} \mathrm{min}^{-1}\right)$ & 14.0 & 15.0 \\
\hline Auxiliary gas flow rate / $\left(\mathrm{L} \mathrm{min}^{-1}\right)$ & 1.00 & 1.2 \\
\hline Nebulizer gas flow rate / $\left(\mathrm{L} \mathrm{min}^{-1}\right)$ & 1.00 & 1.15 \\
\hline Spray chamber & Scott type, double path & Cyclonic \\
\hline Nebulizer & Crossflow & Concentric \\
\hline Sampler and skimmer cones & -- & $\mathrm{Pt}$ \\
\hline Ion lens / V & -- & Auto lens "on" \\
\hline Dwell time / ms & -- & 50 \\
\hline Observation view & Axial & -- \\
\hline Isotope $(\mathrm{m} / \mathrm{z})$ & -- & ${ }^{35} \mathrm{Cl}$ and ${ }^{79} \mathrm{Br}$ \\
\hline Emission lines / nm & $\mathrm{Br}$ (154.065), $\mathrm{Cl}(134.724)$ and $\mathrm{C}(193.091)$ & -- \\
\hline
\end{tabular}


with sample masses up to $500 \mathrm{mg}$ that were placed together the filter paper on the quartz holder. Quartz vessels were previously charged with $6 \mathrm{~mL}$ of absorbing solution (water or ammonium carbonate) and $50 \mu \mathrm{L}$ of $6 \mathrm{~mol} \mathrm{~L}^{-1} \mathrm{NH}_{4} \mathrm{NO}_{3}$ solution were added to the filter paper.

The quartz holder was introduced into the quartz vessel and vessels were pressurized with 20 bar of oxygen using the valve originally designed for the pressure release when using conventional acid digestion system. Then, the rotor was placed inside the oven and the selected microwave heating program was started. The microwave irradiation program used was $1400 \mathrm{~W}$ for $5 \mathrm{~min}$ (optional reflux step) and $0 \mathrm{~W}$ for $20 \mathrm{~min}$ (cooling step). The time for the optional reflux step after the combustion and cooling time were set in accordance with previous studies. ${ }^{32,36}$ After digestion, the pressure of each vessel was carefully released. In this work, each run was performed with a minimum of four vessels. The resultant solutions were diluted with water to $15 \mathrm{~mL}$ for further analysis by ICP OES. The concentration of ammonium nitrate solution, the minimum volume for the ignition process, as well as the mass of paper filter were based on previous work. ${ }^{23}$ Cleaning of vessels and holders was carried out with $6 \mathrm{~mL}$ of concentrated $\mathrm{HNO}_{3}$ in the microwave oven at $1400 \mathrm{~W}$ for $5 \mathrm{~min}$ and $0 \mathrm{~W}$ for 20 min for cooling.

\section{Microwave-assisted extraction using water and alkaline solution}

A microwave-assisted water extraction procedure was also evaluated. In this sense, a mass of $500 \mathrm{mg}$ of sample was placed in the quartz vessel and a volume of $6 \mathrm{~mL}$ of water was added. The same procedure was carried out using $100 \mathrm{mmol} \mathrm{L}^{-1}\left(\mathrm{NH}_{4}\right)_{2} \mathrm{CO}_{3}$. Heating program was $1400 \mathrm{~W}$ for $30 \mathrm{~min}$ (ramp of $10 \mathrm{~min}$ ) and $0 \mathrm{~W}$ for $20 \mathrm{~min}$ (cooling step). The maximum temperature and pressure were $280{ }^{\circ} \mathrm{C}$ and 80 bar, respectively. After cooling, resultants solutions from extraction procedures were diluted with water to $20 \mathrm{~mL}$ in a polypropylene vessel and then centrifuged at $3000 \mathrm{rpm}$ for $10 \mathrm{~min}$ prior to determination by ICP OES.

\section{Results and Discussion}

\section{Determination of bromine and chlorine in cigarette tobacco samples by ICP OES after microwave-assisted extraction using water and alkaline solution}

A sample preparation procedure based on extraction with water in closed vessels was investigated for cigarette tobacco samples. Results obtained for CRM samples using water as extraction solution were with maximum agreement of $70 \%$ and $90 \%$ for $\mathrm{Br}$ and $\mathrm{Cl}$, respectively. The use of alkaline extraction solution did not improve the recoveries for $\mathrm{Br}$ and $\mathrm{Cl}$. Therefore, extraction using water or alkaline solution in closed vessels, even under high pressure and temperature, was not suitable for tobacco preparation for further $\mathrm{Br}$ and $\mathrm{Cl}$ determination.

Optimization of microwave-induced combustion conditions

For the proposed procedure, cigarette tobacco samples were ground in a cryogenic mill and sample pellets of different masses were obtained (100, 250 and $500 \mathrm{mg}$ ). An initial study was performed in order to evaluate the characteristics of the MIC system such as maximum sample mass and maximum pressure during combustion. Using $100 \mathrm{mg}$ of cigarette tobacco samples, the maximum pressure was about 29 bar and even using sample masses up to $500 \mathrm{mg}$ the maximum pressure achieved during combustion was 39 bar that is about $49 \%$ of the maximum pressure recommended by the manufacturer for routine operation (80 bar). After combustion the sample was completely decomposed and negligible brown residues remained in quartz holder. The absorbing solution was completely clear and without visible particles. Therefore, as the procedure was considered safe for digestion up to $500 \mathrm{mg}$ this mass was selected as the maximum mass of sample pellet for the proposed MIC procedure.

Optimization of the absorbing solution for recovery of halogens after microwave-induced combustion

The choice of the absorbing solution is important to achieve suitable recoveries. It is dependent on the analytes nature and should be compatible with the chosen determination procedures. In general, for halogens, acid solutions generally result in analyte losses by volatilization and also interferences in the determination step could be observed when chromatographic and even spectrometric techniques are used. ${ }^{19,32}$ In addition, literature data recommend the use of water or diluted alkaline solutions for further halogen determination after digestion by MIC for different matrices..$^{27,29,32}$ In the present study, the suitability of ammonium carbonate as absorbing solution was evaluated for $\mathrm{Br}$ and $\mathrm{Cl}$. Concentrations of $\mathrm{NH}_{4} \mathrm{CO}_{3}$ solutions of 5 , $10,25,50$ and $100 \mathrm{mmol} \mathrm{L}^{-1}$ and also water were evaluated. Spike recoveries in cigarette tobacco samples were evaluated for each absorbing solution. Previous studies ${ }^{27,29,32}$ also demonstrated that the use of a reflux step allows better recoveries for halogens determination when compared with combustion without reflux step. Results are shown in Figures 1 and 2 for $\mathrm{Br}$ and $\mathrm{Cl}$, respectively. 


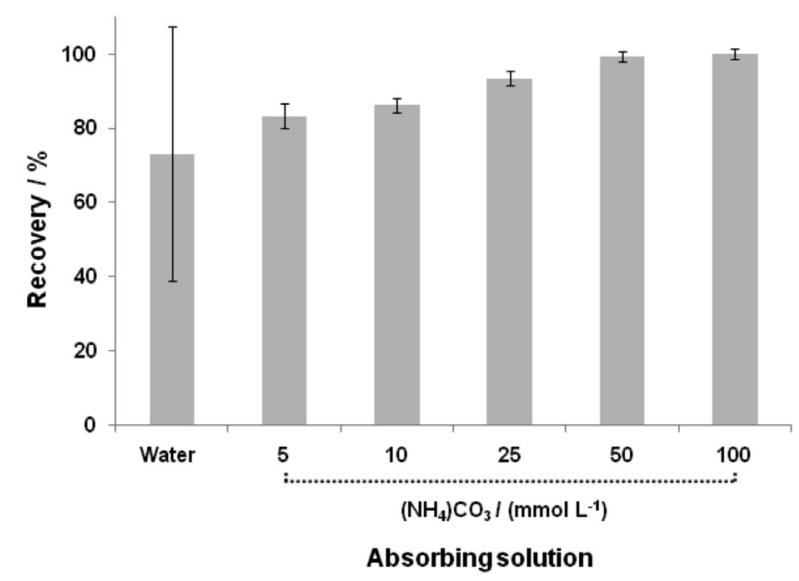

Figure 1. Influence of absorbing solutions for $\mathrm{Br}$ determination in cigarette tobacco samples using $\mathrm{H}_{2} \mathrm{O},\left(\mathrm{NH}_{4}\right)_{2} \mathrm{CO}_{3} 10,25,50$ or $100 \mathrm{mmol} \mathrm{L}^{-1}$ and reflux step. Determination by ICP OES. (error bars are the standard deviation, $\mathrm{n}=3$ ).

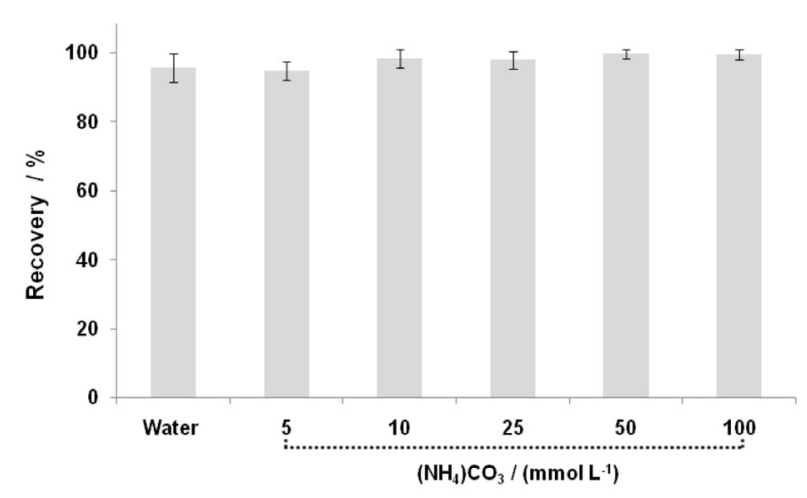

Absorbing solution

Figure 2. Influence of absorbing solutions for $\mathrm{Cl}$ determination in cigarette tobacco samples using $\mathrm{H}_{2} \mathrm{O},\left(\mathrm{NH}_{4}\right)_{2} \mathrm{CO}_{3} 10,25,50$ or $100 \mathrm{mmol} \mathrm{L}^{-1}$ and reflux step. Determination by ICP OES. (error bars are the standard deviation, $\mathrm{n}=3$ ).

Recoveries below $75 \%$ were obtained for $\mathrm{Br}$ using water as absorbing solution (Figure 1). Moreover, the recovery of $\mathrm{Br}$ was dependent of $\mathrm{NH}_{4} \mathrm{CO}_{3}$ concentration. For 5, 10 and $25 \mathrm{mmol} \mathrm{L}^{-1}\left(\mathrm{NH}_{4}\right)_{2} \mathrm{CO}_{3}$ the recoveries were not quantitative.
However, when 50 and $100 \mathrm{mmol} \mathrm{L}^{-1}\left(\mathrm{NH}_{4}\right)_{2} \mathrm{CO}_{3}$ were used as absorbing solutions the recoveries were close to $100 \%$. In Figure 2 it is possible to observe that the recoveries obtained for $\mathrm{Cl}$ using different absorbing solution were not significantly different (ANOVA, 95\% confidence level) even using water. Therefore, $50 \mathrm{mmol} \mathrm{L}-1\left(\mathrm{NH}_{4}\right)_{2} \mathrm{CO}_{3}$ was chosen because it was a compromise condition and allows $\mathrm{Br}$ and $\mathrm{Cl}$ determination in cigarette tobacco samples.

Determination of bromine and chlorine by ICP OES in cigarette tobacco samples after MIC digestion

The proposed procedure was applied to digestion of eight cigarette tobacco samples using $50 \mathrm{mmol} \mathrm{L}^{-1}$ $\left(\mathrm{NH}_{4}\right)_{2} \mathrm{CO}_{3}$ as absorbing solution. The results for $\mathrm{Br}$ and $\mathrm{Cl}$ obtained using ICP OES are shown in Table 2.

Bromine and $\mathrm{Cl}$ concentrations ranged from 29.8 to 53.3 and 3871 to $8249 \mu \mathrm{g} \mathrm{g}^{-1}$, respectively. The relative standard deviations (RSDs) were lower than $7.0 \%$ and $1.9 \%$ for $\mathrm{Br}$ and $\mathrm{Cl}$ determination in commercial cigarette tobacco samples, respectively. Bromine and $\mathrm{Cl}$ were also determined by ICP-MS and no statistical difference (confidence level of 95\%) was observed in comparison with results obtained by ICP OES. Based on this study, the use of concentrated acids or excessive amounts of reagents could be avoided in MIC, reducing blank values and minimizing problems concerning to differences between viscosity of standards and samples. In addition, MIC also reduces the residues generation according to recommendations of green chemistry. The limits of quantification (LOQ) for $\mathrm{Br}$ and $\mathrm{Cl}$ using ICP OES, calculated as ten times the standard deviation of the blank, were 12 and $6 \mu \mathrm{g} \mathrm{g}^{-1}$, respectively.

In order to check the accuracy, MIC was applied for four different CRMs. After digestion, $\mathrm{Br}$ and $\mathrm{Cl}$ were determined by ICP OES. Results are shown in Table 3.

When comparing MIC results and certified values for CTA-VTL-2, significant differences were not observed

Table 2. Results for $\mathrm{Br}$ and $\mathrm{Cl}$ in cigarette samples digested by $\mathrm{MIC}$ using $50 \mathrm{mmol} \mathrm{L}-1\left(\mathrm{NH}_{4}\right)_{2} \mathrm{CO}_{3}$ as absorbing solution and determination by ICP OES and ICP-MS (mean \pm standard deviation, $\mu \mathrm{g} \mathrm{g} \mathrm{g}^{-1}, \mathrm{n}=3$ )

\begin{tabular}{|c|c|c|c|c|}
\hline \multirow[t]{2}{*}{ Samples } & \multicolumn{2}{|c|}{$\mathrm{Br}$} & \multicolumn{2}{|c|}{$\mathrm{Cl}$} \\
\hline & ICP OES & ICP-MS & ICP OES & ICP-MS \\
\hline A & $51.7 \pm 1.5$ & $52.2 \pm 1.4$ & $7086 \pm 100$ & $7075 \pm 98$ \\
\hline B & $34.6 \pm 1.8$ & $34.0 \pm 1.3$ & $4589 \pm 89$ & $4621 \pm 77$ \\
\hline $\mathrm{C}$ & $53.3 \pm 2.0$ & $54.1 \pm 1.4$ & $8249 \pm 79$ & $8201 \pm 88$ \\
\hline D & $42.0 \pm 1.7$ & $41.5 \pm 1.2$ & $6743 \pm 78$ & $6798 \pm 85$ \\
\hline $\mathrm{E}$ & $30.9 \pm 2.0$ & $31.3 \pm 1.3$ & $4253 \pm 47$ & $4268 \pm 42$ \\
\hline $\mathrm{F}$ & $38.1 \pm 2.0$ & $37.1 \pm 1.5$ & $4876 \pm 75$ & $4866 \pm 72$ \\
\hline G & $29.8 \pm 2.1$ & $30.0 \pm 1.3$ & $3871 \pm 22$ & $3865 \pm 23$ \\
\hline $\mathrm{H}$ & $50.9 \pm 2.2$ & $50.1 \pm 2.3$ & $7965 \pm 76$ & $7951 \pm 62$ \\
\hline
\end{tabular}


Table 3. Results for $\mathrm{Br}$ and $\mathrm{Cl}$ in CRM samples digested by MIC using $50 \mathrm{mmol} \mathrm{L}-1\left(\mathrm{NH}_{4}\right)_{2} \mathrm{CO}_{3}$ as absorbing solution and determination by ICP OES (mean \pm standard deviation, $\mu \mathrm{g} \mathrm{g}^{-1}, \mathrm{n}=5$ )

\begin{tabular}{lccccc}
\hline Certified reference material & \multicolumn{2}{c}{ Bromine } & & \multicolumn{2}{c}{ Chlorine } \\
\cline { 2 - 3 } \cline { 5 - 6 } & Certified value & MIC & $14.0 \pm 2.9$ & Certified value & $7350 \pm 210$ \\
\hline CTA-VTL-2 & $14.3 \pm 1.4$ & $<12.0$ & & $7430 \pm 280$ & MIC \\
CTA-OTL-1 & $9.28 \pm 1.06$ & $<12.0$ & $2988^{\mathrm{a}}$ & $2995 \pm 55$ \\
NIST 1547 & $11^{\mathrm{a}}$ & $20^{\mathrm{a}}$ & $19.5 \pm 2.5$ & $360 \pm 19$ & $365 \pm 20$ \\
BCR 60 & & & $10^{\mathrm{a}}$ & $10.5 \pm 1.5$ \\
\hline
\end{tabular}

ainformed value.

for $\mathrm{Br}$ determination ( $t$-test, $95 \%$ confidence level) and an agreement better than $98 \%$ was obtained. Statistical differences ( $t$ test, 95\% confidence level) were also not observed for $\mathrm{Cl}$ concentration obtained by MIC and certified reference value for CTA-VTL-2 and NIST 1547 samples and an agreement better than $99 \%$ was obtained for $\mathrm{Cl}$.

\section{Evaluation of digestion efficiency of proposed method}

In this work, the residual carbon content (RCC) was used in order to evaluate the efficiency of the proposed MIC procedure. Depending on the instrumental technique, the RCC value must be controlled. For MIC using the reflux step, RCC values below $1 \%$ were obtained after decomposition of cigarette tobacco samples. These values can be explained due to the high temperature reached (about $1500{ }^{\circ} \mathrm{C}$ ) during the combustion. In this condition, practically all of the organic materials could be completely decomposed.

\section{Conclusions}

Microwave-induced combustion was suitable for cigarette tobacco digestion for further $\mathrm{Br}$ and $\mathrm{Cl}$ determination by ICP OES. In spite of ICP OES has been considered suitable for analysis of cigarette tobacco samples, ICP-MS could provide lower LODs if it is necessary. Microwave-assisted water extraction presented poor recoveries for $\mathrm{Br}$. The use of MIC showed good performance for cigarette tobacco digestion due to complete oxidation of the organic matrix using a relatively high sample mass $(500 \mathrm{mg}$ ) that allowed obtaining low LODs. The operation was considered safe and a significant reduction of laboratory waste and analysis time was obtained that is important aspect for routine analysis. In addition, it was possible to obtain a single solution suitable for both analytes determination using different analytical techniques and with residual carbon content lower than $1 \%$. Reproducibility was considered suitable for $\mathrm{Cl}$ and
Br with RSDs lower than 7\%. Results obtained for CRMs samples under optimized conditions were in agreement to the certified values.

\section{Acknowledgments}

The authors are grateful to INCT-Bioanalítica, CNPq, CAPES and FAPERGS for supporting this study.

\section{References}

1. International Agency for Research on Cancer (IARC); Tobacco Smoke and Involuntary Smoking, IARC Monographs on the Evaluation of the Carcinogenic Risk of Chemicals to Humans, vol. 83, International Agency for Research on Cancer, WHO: Lyon, France, 2004.

2. Rodgman, A.; Perfetti, T. A.; The Chemical Components of Tobacco and Tobacco Smoke, CRC Press: Boca Raton, FL, USA, 2009, pp. 857-893.

3. Serfor-Armah, Y.; Nyarko, B. J. B.; Akaho, E. H. K.; Kyere, A.W. K.; Osae, S.; Oppong-Boachie, K.; Osae, E. K.; J. Radioanal. Nucl. Chem. 2001, 250, 173.

4. Çam, N. F.; Yaprak, G.; Erduran, M. N.; J. Radioanal. Nucl. Chem. 1999, 242, 273.

5. Martinez, T.; Lartigue, J.; Zarazua, G.; Avila-Perez, P.; Navarrete, M.; Tejeda, S.; Spectrochim. Acta, Part B 2008, 63, 1469.

6. Stephens, W. E.; Calder, A.; Anal. Chim. Acta 2004, 527, 89.

7. Naozuka J.; Veiga, M. A. M. S., Oliveira, P. V.; Oliveira, E.; J. Anal. At. Spectrom. 2003, 18, 917.

8. Hu Q.; Li L.; Shi J.; Chen Z.G.; Wang F.; Wang A.; Spectrosc. Spect. Anal. 2007, 27, 1210.

9. Swami, K.; Judd, C. D.; Orsini, J.; Spectrosc. Lett. 2009, 42, 479.

10. Torrence, K. M.; McDaniel, R. L.; Self, D. A.; Chang, M. J.; Anal. Bioanal. Chem. 2002, 372, 723.

11. Jervis, R. E.; J. Radioanal. Nucl. Chem. 1999, 239, 19.

12. Beckhoff, B.; Kanngießer, B.; Langhoff, N.; Wedell, R.; Wolff, H. eds.; Handbook of Practical X-ray Fluorescence Analysis, Springer: Germany, 2006, pp. 309-407. 
13. Gilliam, J. W.; Soil Sci. Soc. Am. J. 1971, 35, 512.

14. Gaines, T. P.; Parker, M .B.; Gascho, G. J.; Agron. J. 1984, 76, 371.

15. Adriano, D. C.; Pratt, P. F.; Holtzclaw, K. M.; Agron. J. 1973, $65,133$.

16. Crispino, C. C.; Fernandes, K.G.; Kamogawa, M. Y.; Nóbrega, J. A.; Nogueira, A. R. A.; Ferreira, M. M. C.; Anal. Sci. 2007, 23,435 .

17. Di Narda, F.; Toniolo, R.; Bontempelli, G.; Anal. Chim. Acta 2001, 436, 245.

18. Fecher, P. A; Nagengast A.; J. Anal. At. Spectrom. 1994, 9, 1021.

19. Pereira, J. S. F.; Mello, P. A.; Moraes, D. P.; Duarte, F. A.; Dressler, V. L.; Knapp, G.; Flores, E. M. M.; Spectrochim. Acta, Part B 2009, 64, 554.

20. Trevizan, L. C.; Nóbrega, J. A.; J. Braz. Chem. Soc. 2007, 18, 678.

21. Tangen, A.; Lund, W.; Spectrochim. Acta, Part B 1999, 54, 1831.

22. Barin, J. S.; Flores, E. M. M.; Knapp, G. In Trends in Sample Preparation; Arruda, M. A. Z., ed.; Nova Science: New York, 2006, p. 288.

23. Flores, E. M. M.; Barin, J. S.; Paniz, J. N. G.; Medeiros, J. A.; Knapp, G.; Anal. Chem. 2004, 76, 3525.

24. Duarte F. A.; Pereira, J. S. F.; Barin, J. S.; Mesko, M. F.; Dressler, V. L.; Flores, E. M. M.; Knapp, G.; J. Anal. At. Spectrom. 2009, 24, 224.

25. Mesko, M. F.; Mello, P. A.; Bizzi, C. A.; Dressler, V. L.; Knapp, G.; Flores, E. M. M.; Anal. Bioanal. Chem. 2010, 398, 1125.

26. Moraes, D. P.; Mesko, M. F.; Mello, P. A.; Paniz, J. N. G.; Dressler, V. L.; Knapp, G.; Flores, E. M. M.; Spectrochim Acta, Part B 2007, 62, 1065.

27. Flores, E. M. M.; Mesko, M. F.; Moraes, D. P.; Pereira, J. S. F.; Mello, P. A.; Barin, J. S.; Knapp, G.; Anal. Chem. 2008, 80, 1865.
28. Mello, P. A.; Pereira; J. S. F.; Moraes, D. P.; Dressler, V. L.; Flores, E. M. M.; Knapp, G.; J. Anal. At. Spectrom. 2009, 24 , 911.

29. Pereira, J. S. F; Mello, P. A.; Moraes, D. P.; Duarte, F. A.; Dressler, V. L.; Knapp, G.; Flores, E. M. M.; Spectrochim. Acta, Part B 2009, 64, 554.

30. Pereira, J. S. F.; Mello, P. A.; Duarte, F. A.; Santos, M. F. P.; Guimarães, R. C. L.; Knapp, G.; Dressler, V. L.; Flores, E. M. M.; Energy Fuels 2009, 23, 6015.

31. Mello, P. A., Giesbrecht, C. K.; Alencar, M. S.; Moreira, E. M.; Paniz, J. N. G.; Dressler, V. L.; Flores, E. M. M.; Anal. Lett. 2008, 41, 1623.

32. Pereira, J. S. F.; Diehl, L. O.; Duarte, F. A.; Santos, M. F. P.; Guimarães, R. C. L.; Dressler, V. L.; Flores, E. M. M.; J. Chromatogr., A, 2008, 1213, 249.

33. Pereira, J. S. F.; Moraes, D. P.; Antes, F. G.; Diehl, L. O.; Santos, M. F. P.; Guimarães, R. C. L.; Fonseca, T. C. O.; Dressler, V. L.; Flores, E. M. M.; Microchem. J. 2010, 96, 4.

34. Gouveia, S. T.; Silva, F. V.; Costa, L. M.; Nogueira, A. R. A.; Nóbrega, J. A.; Anal. Chim. Acta 2001, 445, 269.

35. Mesko, M. F.; Moraes, D. P.; Barin, J. S.; Dressler, V. L.; Knapp, G.; Flores, E. M. M.; Microchem. J. 2006, 82, 183.

36. Antes, F. G.; Duarte, F. A.; Paniz, J. N. G.; Santos, M. F. P.; Guimarães, R. C. L.; Flores, E. M. M.; Dressler, V. L.; At. Spectrosc. 2008, 29, 157.

Submitted: January 11, 2011

Published online: June 7, 2011

FAPESP has sponsored the publication of this article. 